Bangl. J. Vet. Med. (2009). 7(1) : 233 - 237

\title{
MOLECULAR EPIDEMIOLOGIC STUDY ON ROTAVIRUS INFECTION IN HUMAN AND BIRDS IN ASSOCIATION WITH GASTROENTERITIS
}

\author{
M. S. Islam ${ }^{1}$, M. M. Alam*¹, M. U. Ahmed ${ }^{1}$, A. B. M. Saifuzzaman ${ }^{4}$, N. Kobayashi ${ }^{3}$, M. E. H. Kayesh ${ }^{2}$ and \\ M. S. Uddin ${ }^{1}$ \\ ${ }^{1}$ Department of Medicine, ${ }^{2}$ Department of Microbiology and Hygiene, Bangladesh Agricultural University, \\ Mymensingh, Bangladesh, ${ }^{3}$ Department of Hygiene, Sapporo Medical University School of Medicine, Japan, \\ ${ }^{4}$ Parashuram Veterinary Hospital, Feni
}

\begin{abstract}
A total of 315 stool samples were screened from hospitalized diarrheic human patient and 251 from diarrheic birds from July 2006 to May 2007 by polyacrylamide gel electrophoresis and silver staining (PAGE-SS) technique. Human rotavirus (HRV) and avian rotavirus were detected in $35.28 \%$ stool specimens and $13.15 \%$ bird's faecal specimens respectively. The occurrence of rotavirus infection in human patients of 181-365 days age group was relatively high (45.75\%) while it was $41.82 \%$ in under 5 years old. The birds of 7-12 days age group was found most frequently associated with rotavirus infection and the rate was found $45 \%$.
\end{abstract}

Key words: Avian rotavirus, Human rotavirus, PAGE, Eletropherotypes

\section{INTRODUCTION}

Rotavirus gastroenteritis is a worldwide disease affecting primarily infants, young children and the young of a wide variety of mammalian and avian species (Estes et al., 1983). The disease may occur in humans and animals of all age groups but most frequent and important malady for the young. Human group-A rotavirus is the most important cause of severe diarrhoea in children worldwide (Cook et al., 1990) and rotavirus infection is associated with extensive morbidity and mortality in Bangladeshi children. Almost $25 \%$ of children under 2 years of age who are presented with diarrhoea to the clinical research and service center of the International Centre for Diarrhoeal Disease Research, Bangladesh (ICDDR, B) are infected with rotavirus, and an estimated 1 in 200 Bangladeshi children die from rotavirus diarrhoea by 5 years of age (Unicomb et al., 1997). Avian rota virus were first observed in faeces of young turkey poults with diarrhoea and enteritis in South Dakota (Bergeland et al., 1977) and subsequently were detected in the intestinal contents of diarrhoeic turkey poults in Northern Ireland (McNulty et al, 1978) and in the faeces of diarrhoeic commercial laying hens in England (Jones, et al., 1979). In poultry, both in layer birds and broilers, rotavirus has already been established as the etiological agent of enteritis, originated from viral replication in intestinal epithelium, resulting in diarrhoea and nutrient malabsorption (Snodgrass et al., 1986), which causes an increase in feed conversion ratio and large economic losses to poultry industry (Barnes, 1997). The rotaviruses belonging to the family Reoviridae contain a genome of 11 segments of double stranded RNA (dsRNA) which can be separated into distinct bands by electrophoresis. The migration pattern of the 11 genome segments following electrophoresis of the viral RNA in polyacrylamide gel is called the RNA electropherotype (Estes et al, 1984). Detail studies on the epidemiology of rotavirus associated diarrhoea in human and birds have been preformed in advanced countries. In Bangladesh, very limited works have been done in this context. Recently avian rotavirus like virus was detected in Bangladesh. The number of detection was very low approximately $0.86 \%$ in 232 broiler chicks (Ahmed, 2004). Since sample size was small and detection was too low this result raised a question whether avian rotaviruses do exist at all in Bangladesh. And we felt the necessity to substantiate this finding whether avian rotavirus is responsible for enteritis in chickens and electrophoretic identification of prevailing rotavirus strains in different regions of Bangladesh. The epidemiology of rotavirus associated diarrhoea in human and birds have not been studied in Bangladesh in relation to the prevailing strains. Considering the importance of rotavirus associated diarrhoea, its diverse epidemiological features and for rapid detection of rotavirus infection in human and birds has been studied in this research work.

*Corresponding author’s e-mail: asamahbub2003@yahoo.com

Copyright @ 2009 Bangladesh Society for Veterinary Medicine

All right reserved 1729-7893/0172/09 


\section{S. Islam and others}

\section{MATERIALS AND METHODS}

The present study was carried out during the period from July 2006 to May 2007 in the department of Medicine, Bangladesh Agricultural University (BAU), Mymensingh, Bangladesh.

\section{Collection of samples}

A total of 251 faecal specimens were collected from "Tania” poultry farm, "Jalil” poultry farm, "Babul” poultry farm, the neighboring village poultry farm of BAU Campus, Mymensigh; "Petrol pump” poultry farm, Babuganj, Barisal; "Shaikat" poultry farm, Pazulia, Gazipur and "Pahartauli” poultry farm, Chittagong during the period of July 2006 to May 2007. The faecal specimens were obtained from the cloaca of the broiler birds of 1 to 24 days of age. For each broiler bird, 5-10 gms of sample was collected. Precautions were taken to avoid contamination of one specimen with other. The date of collection, age, clinical signs and environmental history were recorded for each case. After collection the samples were transported to the laboratory and stored at $-20^{0} \mathrm{C}$ until used for electrophoresis. For convenience of the study, the birds were arranged in four groups on the basis of their age: birds having 1 day to 6 days of age, 7 days to 12 days of age, 13 days to 18 days of age and 19 days to 24 days of age. 315 stool specimens were collected from two hospitals namely S. K. Hospital and Mymensingh Medical College Hospital (MMCH), Mymensingh during the period from July 2006 to May 2007. The freshly voided stool specimens were collected during defecation in sterile screw capped container.

The date of collection, age, sex, clinical signs, important clinical history and environmental situations were recorded. For convenience of the study, the human patients were arranged in five groups on the basis of their age: Patients having 28 day to 90 days of age, 91 days to 180 days of age, 181 days to 365 days of age, 366 days to 1825 days and more than 1825 days of age.

\section{Preparation of faecal suspension}

After thawing of the stored samples 1 gm of each specimen was taken in a test tube and $9 \mathrm{ml}$ of PBS (pH 7.4) was added. Faeces and PBS was thoroughly suspended by using a spinmix. The suspension was either used freshly for next phase or stored at $-20^{\circ} \mathrm{C}$ for future use.

\section{RNA extraction and electrophoresis of rotaviral RNA}

This was done according to the method of Laemmli (1970) with some modifications.

\section{Polyacrylamide gel electrophoresis}

Electrophoresis of rotaviral RNA was carried out as per the method of Laemmli (1970) with some modifications.

\section{Silver staining developing and viewing and electropherotyping}

Electropherotyping of viral RNA was carried out in $10 \%$ polyacrylamide slab gels, and silver staining technique as described by Kobayashi et al. (1989).

\section{Statistical analysis}

Statistical analyses were performed using the chi-square test and Fisher's exact test.

\section{RESULTS AND DISCUSSION}

The association of rotavirus infection with diarrhoea in different age group of human patients is presented in Table 1. The percentage of rotavirus associated diarrhoea in 28 day to 90 days, 91 days to 180 days, 181 days to 365 days, 366 days to 1825 days and more than 1825 days age groups of patients were 35\% (7/20), 40\% (18/45), 45.75\% (70/153), 33.37\% (15/45), 1.92\% (1/52), respectively. The highest incidence of rotavirus infection (45.75\%) was observed in the children aged 181 days to 365 days.

During the study period of rotaviral diarrhoea in birds, a total of 251 faecal specimens were examined by PAGE. Of these 33 (13.15\%) specimens showed a characteristics electropherotypic mobility of dsRNA of rotavirus (Figure 2). The migration pattern of all dsRNA detected positive rotaviruses were similar in gel electrophoresis and their migration speed was same as previously designated avian rotavirus group D.

The association of rotavirus infection with diarrhoea in different age group of birds is presented in Table 1 . The percentage of rotavirus associated diarrhoea in 1 day to 6 days, 7 days to 12 days, 13 days to 18 days and 19 days to 24 days age groups of birds were $12.09 \%$ (15/124), 45\% (9/20), 7.40\% (6.81) and 11.53\% (3/26), respectively. 
Table 1. Age-wise prevalence of rotavirus infection in human and birds detected by polyacrylamide gel electrophoresis and sliver staining technique

\begin{tabular}{|c|c|c|c|c|c|c|c|}
\hline \multirow{3}{*}{$\begin{array}{l}\text { Human } \\
\text { Age (days) }\end{array}$} & \multirow{3}{*}{$\begin{array}{l}\text { No. } \\
\text { tested }\end{array}$} & & & \multicolumn{4}{|l|}{ Birds } \\
\hline & & \multicolumn{2}{|c|}{ Positive } & \multirow[t]{2}{*}{ Age (days) } & \multirow[t]{2}{*}{ No. tested } & \multicolumn{2}{|c|}{ Positive } \\
\hline & & No. & $\%$ & & & No. & $\%$ \\
\hline $28-90$ & 20 & 07 & 35.00 & $1-6$ & 124 & 15 & 12.09 \\
\hline $91-180$ & 45 & 18 & 40.00 & $7-12$ & 20 & 09 & 45.00 \\
\hline 181-365 & 153 & 70 & 45.75 & $12-18$ & 81 & 06 & 7.40 \\
\hline 366-1825 & 45 & 15 & 33.34 & $19-24$ & 26 & 03 & 11.53 \\
\hline 1826-Above & 52 & 01 & 1.92 & & & & \\
\hline Total & 315 & 111 & 35.28 & & 251 & 33 & 14.28 \\
\hline
\end{tabular}

A total of 315 diarrhoeal stool specimens examined by PAGE-SS, of which 111(35.28\%) children and adult had rotavirus infection (Table 1) but comparatively lower rate of rotavirus infection have been documented by Alam et al. (1994) who found 20.36\% rotavirus infection in diarrhoeic children (<5 years). Also, Talukder (1999) found $14.21 \%$ rotavirus infection in diarrhoeic children, which is also lower than the present study. This result indicates that there is an increasing trend of rotavirus infection in human in Bangladesh. These variations are not unexpected in biological research, which might have been due to variations in different epidemiologic determinants and techniques used. In this study, the higher rate of infection was recorded in the age group of 181 days to 365 days (45.75\%) as compared to 28 to 90 days (35.00\%), 91 days to 180 days (40.00\%), 366 days to 1825 days (33.34\%) and above 1825 days (1.92\%) age groups (Table 1). There was significant difference between age and rotavirus infection $(\mathrm{p}<0.0001)$. These findings are in conformity with earlier report of Ahmed et al. (1991) and Samarbafzadeh, et al. (2005).

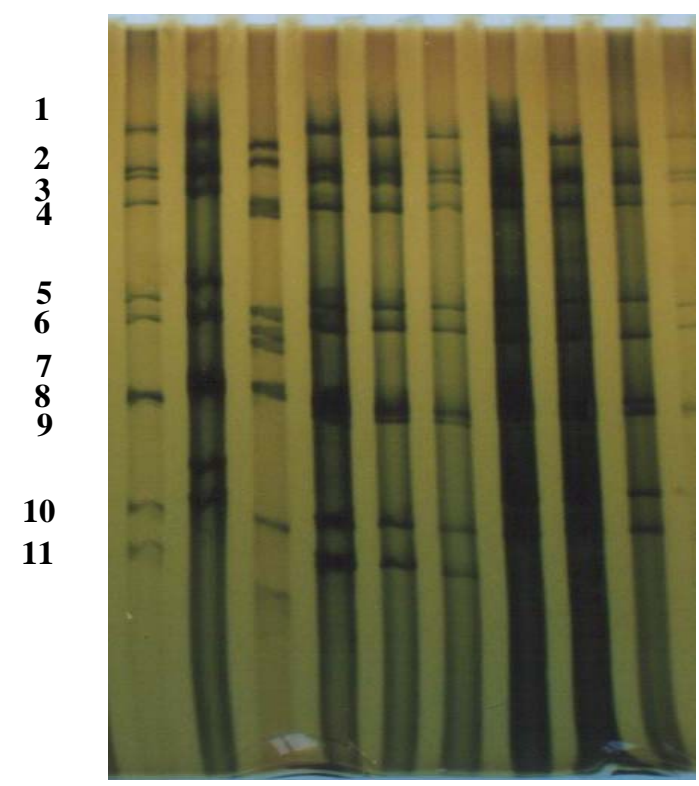

Fig.1. Electrophoretic migration pattern of human rotavirus dsRNA in polyacrylamide gel (In the left side 1-11 numbers indicate the dsRNA segment). 


\section{S. Islam and others}

A total of 251 diarrhoeic feces of birds 1 to 24 days of age were examined by PAGE -SS method, of which 33 birds $(13.15 \%)$ had rotavirus infection, but higher rate of rotavirus infection in birds was recorded $45.3 \%$ by Villarreal et al., (2006). He reported that $48.7 \%$ rotavirus frequencies among samples from flocks with diarrhoea, $46.4 \%$ among flocks with delayed growth, and $30 \%$ among asymptomatic flocks.

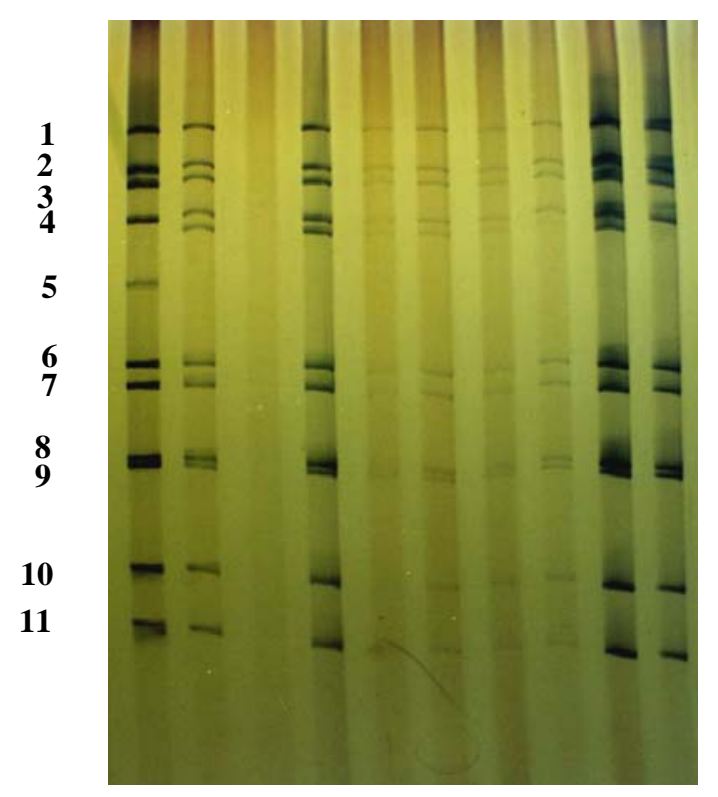

Fig. 2. Electrophoretic migration pattern of avian rotavirus ds RNA in polyacrylamide gel (In the left side 1-11 numbers indicate the dsRNA segment)

This study might be the ever first molecular epidemiologic study of avian rotavirus infection in Bangladesh. Although recently avian rotavirus like virus was detected in Bangladesh and the number of detection was very low approximately $0.86 \%$ in 232 broiler chicks (Ahmed, 2004). Detection rate of avian rotavirus is low in clinical samples in Bangladesh but higher rate of rotavirus infection also have been documented by McNulty et al. (1979) where $40 \%$ of chicken farms and $59 \%$ of birds on these farms in USA were rotavirus seropositive.

The rotavirus infection was found to be highest in bird's age between 7-12 days (45\%) as compared to 1-6 days (12.09\%), 13-18 days (7.40\%) and 19-24 days (11.53\%) age groups. There was statistically significant difference between age and rotavirus infection (Fisher's exact test $<0.003$ ). Ahmed (2004) had detected rotavirus like virus $(0.86 \%)$ only in the age group of 6-12 days. This finding correlates with our present study. Tamehiro et al. (2003) diagnosed $43.7 \%(14 / 32)$ of the avian rotavirus in one or two week old poults. Using electron microscopy technique. Decaesstecker et al. (1988) in Belgium showed a positive frequency of $25 \%$ for AvRV in 102 diarrhoeic fecal samples from broiler chicken up to a month old. The present study will help in epidemiological investigations to characterize individua l virus isolates by genetic analyses of their dsRNA migration patterns of potential importance.Considering their broad host spectrum, their reassortment events there might have a strong impact on the zoonotic potential of rotavirus. In addition to mutational antigenic drift and shift, zoonosis might therefore contribute to potential replacement of current rotavirus strains.

To understand the epidemiology of rotavirus infection in man and birds, however, further epidemiological studies in relation to the association of other causal agents with diarrhoea, the strain of virus, antigenic structures with reference serotypes and zoonotic potential of rotavirus is necessary before introduction of vaccines against rotavirus diarrhoea in Bangladesh. 
In these regard further studies of both human and avian rotaviruses should be continued in different parts of the country to know the real status of rotavirus infection in Bangladesh, to understand the genetic diversity and evolutionary mechanisms of human rotavirus to develop a strategy for prevention of rotavirus associated diarrhea.

\section{REFERENCES}

1. Ahmed MS (2004). Detection of avian rotavirus like virus in broiler chickens in Mymensingh and Gazipur. Thesis MS (Vet. Sci.) in Medicine, Department of Medicine Bangladesh Agricultural University, Mymensingh, Bangladesh.

2. Ahmed MU, Urasawa S, Taniguchi K, Urasawa T, Kobayashi N, Wakasugi F, Islam AIMM and Sahikh HA (1991). Analysis of human rotavirus strains prevailing in Bangladesh in relation to nationwide floods brought by the 1988 Monsoon. Journal of Clinical Microbiology 29 : 2273 - 2279.

3. Alam MM, Huque AKMF, Nigar S, Haque M, Choudhury NS and Ahmed MU (1994). Rotavirus infection in children and calves in association with acute gastroenteritis. Bangladesh Veterinary Journal 28: 35 - 40.

4. Barnes HJ (1997). Virology enteric infections In: Saif, Y.F. Diseases of poultry $10^{\text {th }}$ edn. Ames: Iowa state University press p 685 - 686.

5. Bergeland ME, McAdaragh JP and Stotz I (1977). Rotaviral enteritis in turkey poults. Proc. $26^{\text {th }}$ Western Poultry Disease conference pp 129-130.

6. Cook SMRI, Glass CW, Lebaron and Ho MS (1990). Global seasonality of rotavirus infections. Bull. W.H.O. 68 : 171 177.

7. Decaesstecker M, Charlier G and Meulemans G (1988). Epidemiological study of enteric viruses in broiler chickens: Comparison of tissue culture and direct electron microscopy. Avian Pathology 17:477-486.

8. Estes MK, Graham DY and Dimitrov DH (1984). The molecular epidemiology of rotavirus gastroenteritis. Progress in medical virology $29: 1-22$.

9. Estes MK, Palmer EL and Obijeski JF (1983). Rotaviruses; a review. Current Topics in Microbiology and Immunology 105: 123-184.

10. Jones RC, Hughes CS and Henry RR (1979). Rotavirus infection in commercial laying hens. Veterinary Record 104: 22.

11. Kobayashi N, Lintag IC, Urasawa T, Tangiguchi, K, Saniel MC and Urasawa S (1989). Unusual human rotavirus strains having subgroup 1 specificity and long RNA electrophoerotype. Arch. virol 109: 11-23.

12. Laemmli UK (1970). Cleavage of structural proteins during the assembly of the bacteriophage $\mathrm{T}_{4}$. Nature. Lond. 227: 680-685.

13. McNulty MS, Allan GM and Stuart JC (1978). Rotavirus infection in avian species. Veterinary Record 103: 319-320.

14. McNulty MS, Allan GM, Todd D and McFerran JB (1979). Isolation from chickens of a rotavirus lacking the rotavirus group antigen. Journal of General Virology 55: 405-413.

15. Samarbafzadeh A, Tehrani EM, Makvandi M and Taremi M (2005). Epidemiological aspects of rotavirus infection in Ahwaz, Iran. Journal of Health, Population and Nutrition $23: 245-249$.

16. Snodgrass DR, Terzolo HR, Sherwood D, Campbell I, Menzies JD and Synge BA (1986). Etiology of diarrhoea in young calves. Veterinary Record 119:31-34.

17. Talukder MRI (1999). Rotavirus diarrhoea in human and animals in Mymensingh. Thesis MS (Vet. Sci.) in Medicine, Department of Medicine Bangladesh Agricultural University, Mymensingh, Bangladesh.

18. Temehiro CY, Alfieri AF, Medict KC and Alferi AA (2003). Segmented double-stranded genomic RNA viruses in fecal samples from broiler chicken. Brazilian Journal of Microbiology Vol. 34 No. 4 Sao Paulo.

19. Unicomb LE, Kilgore PE, Faruque ASG, Hamadani JD, Fuchs GJ, Albert MJ and Glass RI (1997). Anticipating rotavirus vaccines hospital based surveillance for rotavirus diarrhoea and estimates of disease burden in Bangladesh. The Pediatric Infectious Disease Journal 16: 947-951.

20. Villarreal LYB, Uliana G, Valenzuela C, Chacon JLV, Saidenberg ABS, Sandches AA, Brandao PE, Jerez JA and Ferreira AJP (2006). Rotavirus detection and isolation from chickens with or without symptoms .Brazilian Journal of Poultry Science 8: 187-191. 